\title{
Interleukin-10-regulated tumour tolerance in non-small cell lung cancer
}

Julius Malte Vahl ${ }^{1,4}$, Juliane Friedrich ${ }^{1}$, Susanne Mittler ${ }^{1}$, Sonja Trump ${ }^{1}$, Lisanne Heim ${ }^{1}$, Katerina Kachler ${ }^{1}$, Liubov Balabko ${ }^{1}$, Nicole Fuhrich ${ }^{2}$, Carol-Immanuel Geppert ${ }^{2}$, Denis lulian Trufa ${ }^{3}$, Nina Sopel ${ }^{1}$, Ralf Rieker $^{2}$, Horia Sirbu ${ }^{3}$ and Susetta Finotto*,1

${ }^{1}$ Laboratory of Cellular and Molecular Lung Immunology, Department of Molecular Pneumology, Friedrich-Alexander-Universität Erlangen-Nürnberg (FAU), Hartmannstraße 14, Erlangen 91052, Germany; ${ }^{2}$ Institute of Pathology, Friedrich-Alexander-Universität Erlangen-Nürnberg (FAU), Krankenhausstraße 8-10, Erlangen 91054, Germany and ${ }^{3}$ Department of Thoracic Surgery, FriedrichAlexander-Universität Erlangen-Nürnberg (FAU), Krankenhausstraße 12, Erlangen 91054, Germany

Background: Lung cancer is the most life-threatening cancer type worldwide. Treatment options include surgery, radio- and chemotherapy, as well as the use of immunomodulatory antibodies. Interleukin (IL)-10 is an immunosuppressive cytokine involved in tumour immune escape.

Methods: Immunohistochemistry $(\mathrm{IHC})$ on human lung surgery tissue as well as human tumour cell line cultures, FACS analysis, real-time PCR and experimental lung cancer.

Results: Here we discovered a positive correlation between IL-10 and IL-10 receptor (IL-10R) expression in the lung with tumour diameter in patients with lung cancer (non-small cell lung cancer), the most life-threatening cancer type worldwide. IL-10 and IL10R were found induced in cells surrounding the lung tumour cells, and IL-10R was mainly expressed on the surface of Foxp- $3^{+}$ T-regulatory lymphocytes infiltrating the tumour of these patients where its expression inversely correlated with programmed cell death 1. These findings were confirmed in translational studies. In a human lung adenocarcinoma cell line, IL-10R was found induced under metabolic restrictions present during tumour growth, whereby IL-10 inhibited PDL1 and tumour cell apoptosis.

Conclusions: These new findings suggest that IL-10 counteracts IFN- $\gamma$ effects on PD1/PDL1 pathway, resulting in possible resistance of the tumour to anti-PD1/PDL1 immunotherapy.

Lung cancer is the most common cancer type with the highest cancer-related mortality worldwide (Ferlay et al, 2015). Histologically, it is subgrouped into small cell lung cancer and non-small cell lung cancer (NSCLC), which can be further subgrouped into adenocarcinoma (ADC) and squamous cell carcinoma (SCC). Unfortunately, the frequently late clinical detection going along with high pathological stage and the absence of curative end-stage treatment options results in a low 5 years average survival rate (Naruke et al, 1988; Goldstraw et al, 2007). Current treatments are so far excision, radio- and chemotherapy, as well as the use of immune-modulating antibodies (Besse et al, 2014). For that reason, it is important to investigate key regulators of lung cancer development and progression.

In this context, interleukin (IL)-10, an acid-sensitive homodimeric cytokine, is regarded as a major immunosuppressive, pro-tumoural cytokine. It is a pleiotropic molecule with antiinflammatory function, regulating autoimmunity, cell proliferation, survival, apoptosis and angiogenesis (Hatanaka et al, 2001), and is mainly secreted by M2-macrophages, Tregs and Th2-cells. In addition, bronchial epithelial cells, which are the initial source of

*Correspondence: Professor S Finotto; E-mail: susetta.finotto@uk-erlangen.de

${ }^{4}$ The present work was performed in fulfilment of the requirements for obtaining the degree 'Dr med' for Julius Vahl.

Received 30 June 2017; revised 3 August 2017; accepted 30 August 2017; published online 10 October 2017

(C) 2017 Cancer Research UK. All rights reserved 0007-0920/17 
NSCLC, are also capable of releasing IL-10 (Teng et al, 2011; Dennis et al, 2013).

The clinical relevance of IL-10 in NSCLC has been frequently proofed by presenting its pro-tumoural qualities. IL-10 is notably produced by tumour-associated macrophages (TAMs) (Montuenga and Pio, 2007), CD $4{ }^{+}$Tregs or even infiltrating CD8 ${ }^{+}$T-cells and tumour cells themselves (Hatanaka et al, 2000), alhough it has been shown that not only the serum level of IL-10 (Petrovic et al, 2013), but especially the amount of IL-10 released by TAMs is correlating with non-response to anti-tumoural therapy (Zeni et al, 2007; Wang et al, 2011) and that Tregs in NSCLC overexpress IL-10 due to Foxp-3 promoter demethylation (Ke et al, 2016). Finally, incomplete surgery increases the level of IL-10 (Rybojad et al, 2013), which also has the potential to promote metastasis (Zeng et al, 2010). At the cellular basis, IL-10 impairs Th1-cells, antigenpresenting cells (APC) (Huang et al, 1998; Sharma et al, 1999; Coussens and Werb, 2002; Jarnicki et al, 2006) and M1macrophages (Almatroodi et al, 2016), and in this context programmed death-1 (PD1) is regarded as an excellent marker of T-cell exhaustion (Wherry, 2011; Mandai et al, 2016). However, in addition to the knowledge on the immunosuppressive, protumoural function of IL-10, its function depends on its application (Dennis et al, 2013; Almatroodi et al, 2016; Zhang et al, 2016; Naing et al, 2016a).

Thus, our present study aimed at understanding the role of IL10-related immune molecular tumour escape regulation mechanisms in NSCLC, to gather new treatment ideas by multilateral investigations on a human cohort of patients.

\section{MATERIALS AND METHODS}

Human subjects and study population. This study is performed at the Friedrich-Alexander University Erlangen-Nürnberg, Germany, and was approved by the ethics review board of the University of Erlangen (Re-No: 56_12B; DRKS-ID: DRKS00005376). Patients, who suffered from NSCLC, gave their approval and were enroled in this study. The histological types of lung cancer are classified according to the World Health Organization (2010). The staging of lung cancer was based on the Cancer TNM Staging Manual, formulated by the International Association for the Study of Lung Cancer (2010). Tissue samples are divided into TU (solid tumour tissue) and CTR (tumour-free area, at least $5 \mathrm{~cm}$ away from the solid tumour).

IHC of paraffin-embedded tissue sections. Lung tissue samples were fixed in $10 \%$ formalin and processed for paraffin embedding. Blocks were sectioned and stained with antibodies for specific target antigens: $\alpha$ IL-10 (Acris, PM1121, Herford, Germany), $\alpha$ IL10R (Abcam, ab197666, Cambridge, UK), $\alpha \mathrm{CD} 3$ (Zytomed, RBK024, Berlin, Germany), $\alpha$ PD1 (Zytomed, 516-18632) and aTTF1 (Dako, M3575, Hamburg, Germany). Stained slides were scanned and digital hole slide images were performed using a digital slide scanner (Scan 150, 3D Histech Ltd, Budapest, Hungary) at the task group on digital pathology at the Institute of Pathology, Friedrich-Alexander-Universität Erlangen-Nürnberg (FAU), Erlangen, Germany. Hole slide images were visualised by the CaseViewer (Version 2.0, 3D Histech Ltd). The immune reactive score (IRS) or the area fraction quantification was analysed with ImageJ software Version 1.46 (Bethesda, MD, USA), open source by Wayne Rasband. The detailed quantification method is described in the supplements.

IHC quantification. The IRS by Remmele and Stegner respects the percentage of coloured cells and the intensity of the particular colour ( $0-12$ points can be scored in total). To perform this quantification, five pictures with a $\times 20$ objective of an Observer D.1 microscope (Zeiss Microscopy GmbH, Jena, Germany) were made of each patient using AxioCAM MR ZEN2 pro software (Zeiss Microscopy $\mathrm{GmbH}$ ) and analysed as follows:

\begin{tabular}{|l|c|c|c|c|}
\hline & $\begin{array}{c}\text { No } \\
\text { staining }\end{array}$ & $\begin{array}{c}\text { Light } \\
\text { staining }\end{array}$ & $\begin{array}{c}\text { Medium } \\
\text { staining }\end{array}$ & $\begin{array}{c}\text { Strong } \\
\text { staining }\end{array}$ \\
\hline $0 \%$ Positive cells & IRS $=0$ & IRS $=0$ & IRS $=0$ & IRS $=0$ \\
\hline $1-9 \%$ Positive cells & IRS $=0$ & IRS $=1$ & IRS $=2$ & IRS $=3$ \\
\hline $10-50 \%$ Positive cells & IRS $=0$ & IRS $=2$ & IRS $=4$ & IRS $=6$ \\
\hline $51-80 \%$ Positive cells & IRS $=0$ & IRS $=3$ & IRS $=6$ & IRS $=9$ \\
\hline $81-100 \%$ Positive cells & IRS $=0$ & IRS $=4$ & IRS $=8$ & IRS $=12$ \\
\hline
\end{tabular}

The area fraction is the quotient between the area (pixel) of coloured cells and all cells of an image (stained and unstained, but no interspace) calculated with Image J software (Version 1.46r) after receiving the scanned human arrays of lung tissue from patients suffering from NSCLC and importing the graphical material in case viewer software (Version 2.0, 3D Histech Ltd). These pictures were opened with ImageJ and area measurements were done by using its colour threshold function, customising a detection raster including hue, colour saturation and brightness, which allowed us to mark and measure the cells via analysis function quite accurate. The area fraction multiplied by 100 produces the percentage of stained cells.

Quantitative real-time PCR. Cultured cells were absorbed in peqGOLD RNA Pure (peqLab 30-1010, Erlangen, Germany). Human lung tissue samples were prepared with the help of Precellys (Bertin Technologies, REF KTO3961-1-009.2, Rockville, MD, USA) and Minilys Tissue Homogenizer (Bertin Technologies). RNA was isolated by a modified phenol-chloroform method described in Cold Spring Harbor Laboratory Press, Cold Spring Harbor, NY, USA, 2001 (Kirby, 1956). RNA was transcribed into cDNA by using the RevertAid First Strand cDNA Synthesis Kit (Thermo Scientific, K1621, Erlangen, Germany) according to the manufacturer's protocol. The following specific genes were measured: HPRT, STAT3, PD1, PDL1, IL-10, IL-10RA and HIF1A. Primer sequences are listed in Supplementary Table S1.

Experimental design of the A549 lung ADC cell line. A549 cells are human lung ADC alveolar basal epithelial cells, generated in 1972 by Donald Giard, originating primarily from a 58 -year-old Caucasian male. In vitro, A549 grow in monolayer and are widely used in research. $3 \times 10^{5}-10^{6}$ A549 cells were cultured with $10 \%$ FCS containing medium (Gibco F-12 Nut Mix, Thermo Scientific, complemented with $1 \%$ penicillin and streptomycin and $1 \% \mathrm{~L}$ glutamine) or $0.4 \%$ FCS (serum starvation) at $37^{\circ} \mathrm{C}$ and $5 \% \mathrm{CO}_{2}$. To analyse the effect IL-10, A549 cells were cultured for $24-48 \mathrm{~h}$ with rhIL-10 (Immunotools, 11340105, Friesoythe, Germany). Cells were collected and used for flow cytometric analysis or RNA extraction.

Flow cytometry. A549 were stained with the following specific antibodies: $\alpha$-pSTAT3 (BD Bioscience, 550474, Alexa Fluor 647, San Diego, CA, USA) according to the manufacturer's protocol, $\alpha$-IL-10R (Biolegend, 308804, PE, San Diego, USA), $\alpha$ PD1 (Biolegend, 329908, APC), $\alpha$ PDL1 (Biolegend, 329908), $\alpha$-FAS (Miltenyi Biotec,130099738, APC, Bergisch Gladbach, Germany) and $\alpha$ FASL (Biolegend, 306407, PE). Apoptosis assay was performed with Annexin V (BD Pharmingen, 550474, APC, San Diego, CA, USA) and propidium iodide (BD Pharmingen, $5166211 \mathrm{E})$ according to the manufacturer's instructions. Measurements were done at the BD, FACS Calibur \& Flow Supply (342975). Evaluation was performed with FlowJo-v10 software (Flowjo, LLC, Ashland, OR, USA).

Mice. Balb/c mice were purchased from Janvier (Charles River, Sulzfeld, Germany). Mice were kept in the animal care facility of 
the Kussmaul Campus, Hartmannstrasse 14, Erlangen-Nuremberg, under a $12 \mathrm{~h}$ light/dark cycle. Food and tap water were provided ad libitum. All animal procedures were approved by the respective governments in accordance to the German animal protection law and carried out by skilled experimenters. License Az. 54-2532.1-36/13.1

Murine model of lung ADC and tumour growth measurement. Female Balb/c mice (6-8 weeks) were intravenously injected with $10^{6}$ LL/2-luc-M38 Bioware Cell line (Caliper LifeSciences, Hopkinton, MA, USA). At the described time points, mice were injected intraperitonally with luciferin $\left(15 \mathrm{mg} \mathrm{ml}^{-1}\right)$ and anaesthetised with isoflurane for the luciferase activity measurement. Luciferase activity was measured with the Caliper IVIS system.

Statistical evaluation. Statistical analysis excluding correlations were done with the Student's/Gosset's unpaired, two-tailed $t$-test $\left({ }^{\star} P<0.05,{ }^{*} P<0.01\right.$ and $\left.{ }^{* *} P<0.001\right)$ and is presented with mean values \pm s.e.m.

Correlations were examined by importing data, which needed to be correlated, in XY-tables of GraphPad Prism 7 software (GraphPad Software, Inc., La Jolla, CA, USA), diagram it with linear regression curve and perform the two-tailed Pearson's correlation analysis to get the $R$ - and $P$-value $\left({ }^{\star} P<0,05\right.$; ${ }^{\star *} P<0,01$; $\left.{ }^{* *} P<0,001\right)$.

\section{RESULTS}

Increased IL-10 expression in the lung control region (CTR), surrounding the tumour, directly correlated with the tumour diameter in patients who suffered from ADC. In this study, we started analysing the micro-anatomical expression of the immunosuppressive cytokine IL-10 in the lung of patients that underwent surgery because of NSCLC. To this aim, we first did IHC on histological tissue arrays, which we generated by using lung tissues selected from the tumoural and control regions of our cohort of patients $(n=48)$ who underwent surgery because of NSCLC. Lung samples were collected after surgery at the Thoracic Surgery Department of the FAU in Erlangen, directly processed at the adjacent Pathology Institute and transported immediately kept cold to our department. The characteristics of these patients are shown in Table 1.

To understand if IL-10 was co-localised with tumour cells expressing thyroid transcription factor-1 (TTF1), we first double immunostained the histological sections with an antibody directed to IL-10 followed by antibody to TTF1 (Figure 1A). The negative controls for IHC used in this study are shown in Supplementary Figure S1. In Figure 1B we then quantified the number of IL-10positive cells in the tissue arrays and found that the number of IL10 -positive cells was upregulated in the control region of patients with $\mathrm{ADC}$ as compared with the respective tumour region, as well as to the SCC control and tumour region. Overall, this significance held true also when all patients of the cohort with NSCLC were analysed (Figure 1B, right panel). We then analysed $I L-10$ mRNA from a larger cohort of these patients with NSCLC and confirmed that the control region of patients with ADC had more IL-10 mRNA (Figure 1C) as compared with those bearing a SCC. Interestingly, we found that $I L-10$ mRNA was not downregulated in the tumour region of these $\mathrm{ADC}$ patients, indicating the presence of inhibitory mechanisms on IL-10 protein translation in the tumour region of patients with ADC. At the RNA level also, we found a downregulation of $I L-10$ mRNA in the tumoural region of patients with SCC as compared with their control region. In summary, we have found a downregulation of IL-10 in the tumoural region of patients with NSCLC (Figure 1B, right-handside panel). We next correlated $I L-10$ mRNA expression with the tumour diameter and found a direct positive correlation between these two parameters in the control region of patients with ADC and, in general, in NSCLC patients analysed in this study (Figure 1D), indicating a possible relationship between $I L-10$ mRNA expression in cells surrounding the tumour and the size of the tumour. To better characterise the cells expressing IL-10 in the lung tumour, we next immuno-double stained the tissue arrays with anti-IL-10 and anti-CD3 antibodies to understand whether IL-10 was produced by T-lymphocytes in NSCLC. As shown in Figure $1 \mathrm{E}$ and $\mathrm{F}$, we could not see a significant co-localisation of these two markers in lung tissues. Moreover, CD3 was found elevated in the tumoural region of patients who suffered of ADC (Figure $1 \mathrm{G}$ ), confirming that the main type of cells producing IL-10 in the lung of patients with ADC were not T-lymphocytes. Morphologically, we assume that these IL- $10^{+}$brown stained cells are mainly macrophages and leucocytes, and rarely even tumour cells.

Enhanced PD1 expression in the tumoural region of patients who suffered from NSCLC is directly correlated with CD3 and PDL1 levels. The peripheral tolerance has in health an important role on maintaining a homeostatic immune system. PD1 binds to PDL1 as an important component of this peripheral tolerance. However, PDL1 expressed on cancer cells or on myeloid cells infiltrating the tumour has an inhibitory role in the development of anti-tumour immune responses. PDL1 has been shown to be induced by IFN- $\gamma$, an inhibitor of IL-10 (Kuang et al, 2009; Zhang et al, 2009).

To start to investigate the relationship between IL-10 and the PD1/PDL1 expression we double stained our tissue arrays with PD1 and IL-10 (Figure 2). Here we found by double IHC that IL10-positive cells, shown in brown in Figure $2 \mathrm{~A}$ and $\mathrm{B}$, were topographically located in proximity of $\mathrm{PD} 1$ positive cells shown in blue. By quantification, we found that PD1 elevated cells, similar to $\mathrm{CD} 3$, were induced in the tumoural region of patients with ADC and SCC (Figure 2C). Moreover, a direct positive correlation was found between PD1 and PDL1 in SCC specifically and in NSCLC, in general (Figure 2D and E, respectively) and between $\mathrm{CD} 3$ and PD1 in the tumoural region of patients with ADC (Figure 2F). We then concluded that cells other than T-cells, such as macrophages or other cells expressing IL-10, would be mapping in proximity of PD1-expressing cells.

In conclusion, here we discovered that the distribution of $\mathrm{CD}^{+}$ and $\mathrm{PD} 1^{+}$stained cells is strongly correlated in lung tissues from NSCLC, showing a rise of them in the tumour region, especially in the tumour region of patients with ADC, compared to the control regions of each cancer type. Moreover, $\mathrm{IL}-10^{+}$and $\mathrm{PD} 1^{+}$cells are seen to infiltrate the tumour tissue and are found next to each other.

Enhanced expression of IL-10R in the control region in patients who suffered from NSCLC. We next analysed the expression of the IL-10R. This cytokine receptor is known to be expressed on T-cells. Specifically, the IL-10/IL-10R system is believed to mediate immunosuppressive functions of T-regulatory (Treg) cells. We next asked about the localisation of IL-10R $\alpha$-chain in the lung tissues of patients with NSCLC. The IHC on histological arrays are shown in the Figure $3 \mathrm{~A}$ and $\mathrm{B}$.

Here we detected a predominant localisation of $\mathrm{IL}^{-10 \mathrm{R}^{+}}$cells in the control region of patients with SCC (Figure 3C). IL-10R mRNA was upregulated in the tumoural region of lung tissue from patients affected by lung $\mathrm{ADC}$ as compared with the tumoural region bearing squamous carcinoma cells (Figure 3D). Moreover, we found that both, the control and the tumoural region of ADC expressed high levels of IL-10R as seen in SCC CTR. In conclusion, our findings suggest that IL-10 can directly or indirectly affect tumour surrounding or infiltrating cells as well as the tumour cells. 
Table 1. Clinical characteristics of the patient cohort

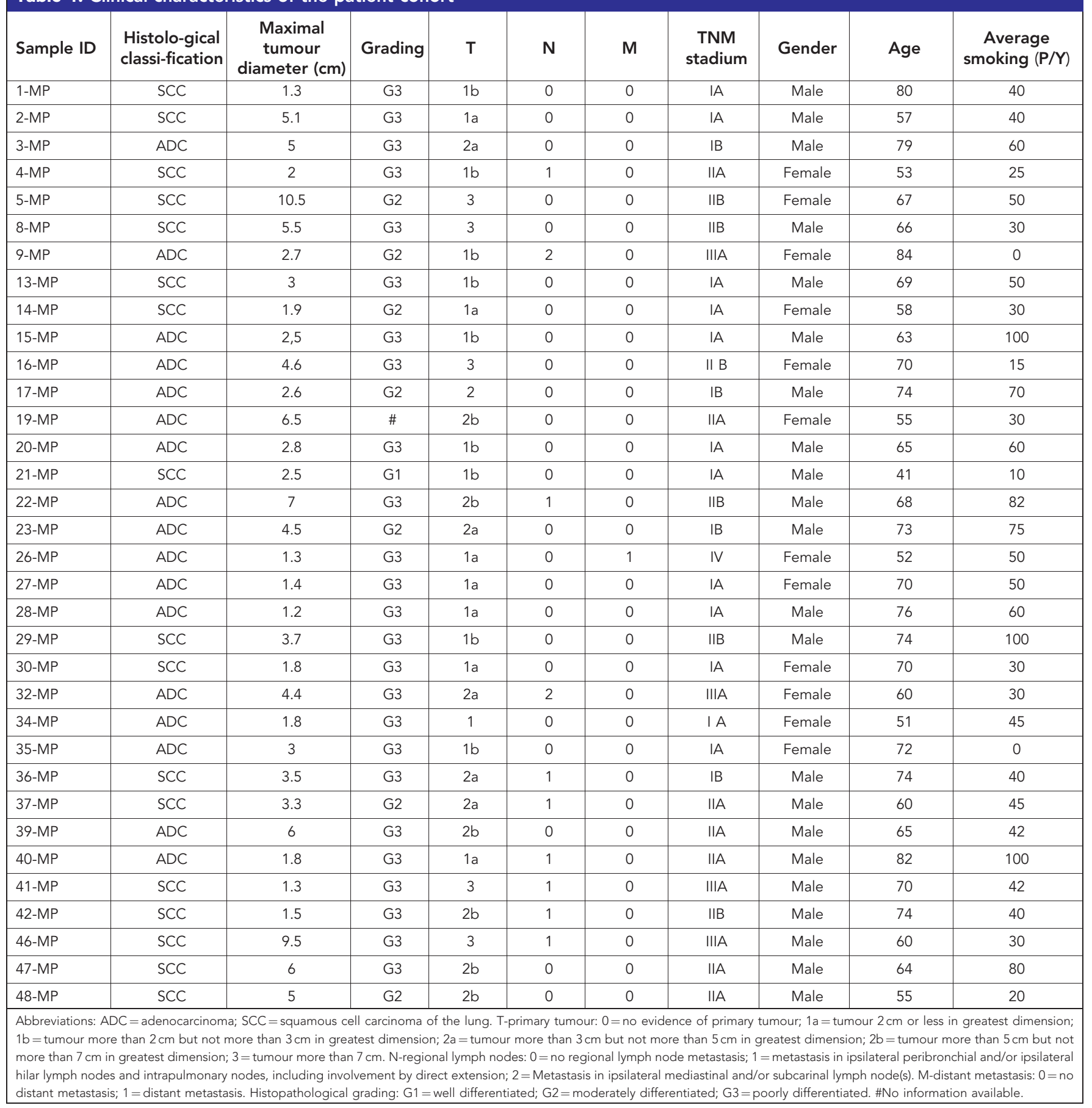

IL-10R expression directly correlated with the tumour diameter and PD1 levels and is upregulated in Foxp- $3^{+}$Treg cells infiltrating the tumoural region of patients with ADC. We next wanted to closer analyse the relationship of $I L-10 R$ mRNA expression in the tumour region and the tumour diameter in NSCLC. In patients with ADC, we found a direct correlation between IL-10R and the tumour diameter as defined by CT at the time of the surgery (Figure 3E). As IL-10R and PD1 directly correlated in the tumoural region of patients with SCC (Figure 3F), we next asked whether PD1, such as IL-10R, would correlate with the tumour diameter in the tumour (Figure 3G). However, we could not find a direct correlation, indicating that cells expressing IL-10R are distinct from PD1-expressing cells. Finally, we analysed
IL-10R expression on $\mathrm{CD}^{+}{ }^{+}$T-cells in freshly isolated lung cells from two patients with ADC. Here we found increased number of Foxp- $3^{+}$Treg cells expressing IL-10R in their tumoural region (Figure $3 \mathrm{H}$ ). In conclusion, the data indicate that in the tumour region of patients with SCC, PD1 and IL-10R are co-localised whereas in ADC IL-10R maps with Foxp-3.

In SCC, but not in ADC, IL-10R directly correlated with PDL1 and HIF1- $\alpha$ expression. We next correlated IL-10 and IL-10R, and found a very good positive correlation between this cytokine and its receptor both in the control but especially in the tumoural region of the lung of patients with ADC (Figure 4A). As we described above, we think that the main cells producing IL-10 are 
A $\quad H 50 \mu m$ small square

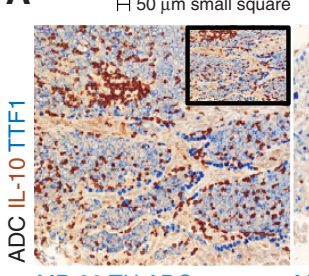

MP-20 TU ADC

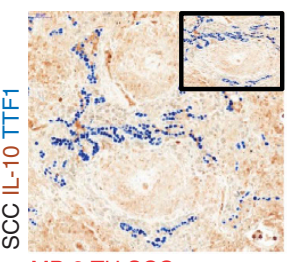

MP-2 TU SCC

\section{E}

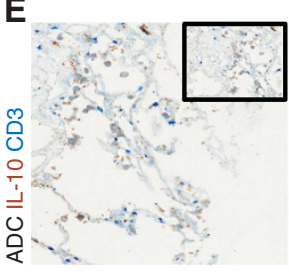

MP-26 CTR ADC

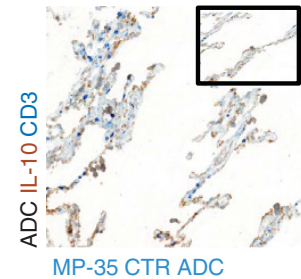

$\mapsto 50 \mu \mathrm{m}$ big square

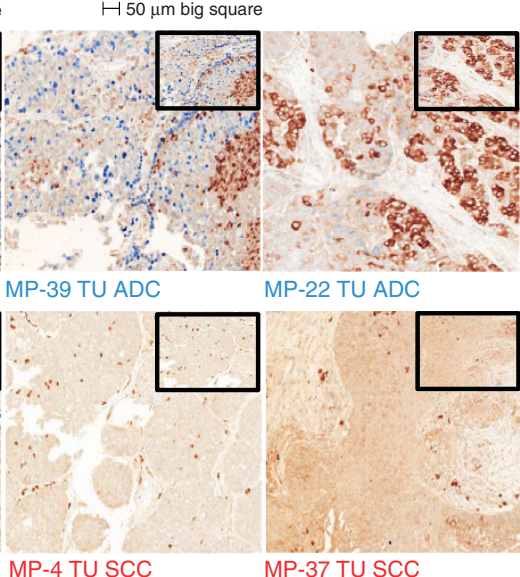

B

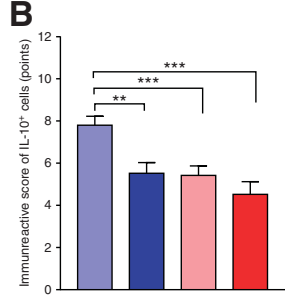

$D_{8}$

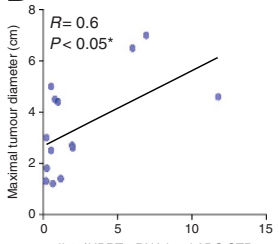

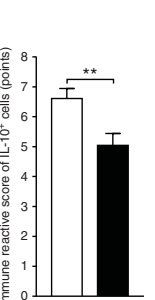

C
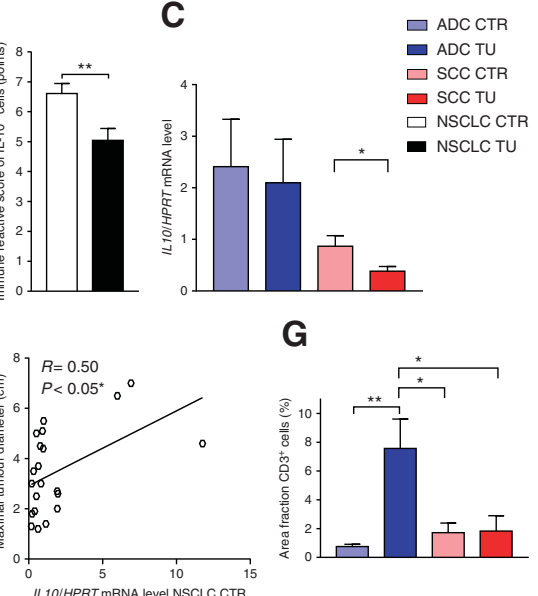

G

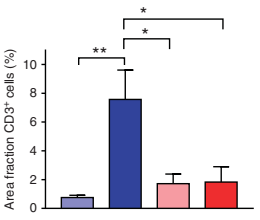

$F$
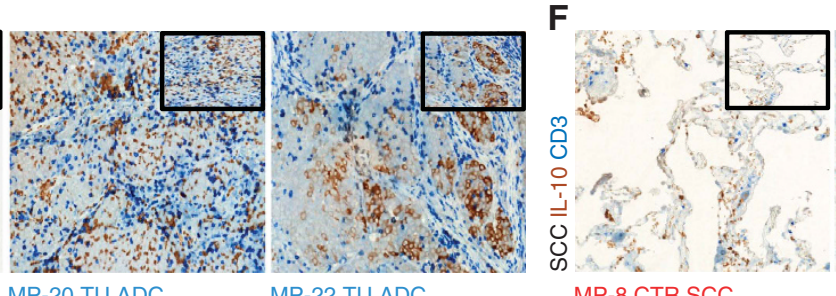

MP-20 TU ADC

MP-22 TU ADC

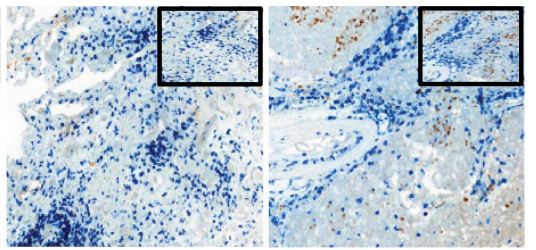

MP-26 TU ADC

MP-39 TU ADC

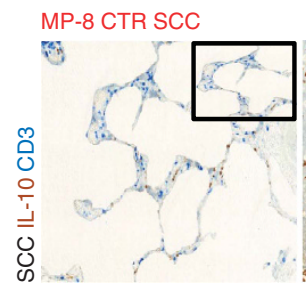

MP-13 CTR SCC

Figure 1. Increased IL-10 expression in the lung control region (CTR) directly correlated with the tumour diameter in patients who suffered from ADC. (A) Immunostaining of IL-10 (brown) and TTF1 (blue) was performed on paraffin-embedded tissue sections from TU of patients who suffered from ADC or SCC. (B) Bar charts represent the immune-reactive score of IL-10+ cells analysed with the Remmele and Stegner's IRS (ADC CTR $n=9$, ADC TU $n=11$, SCC CTR $n=8$, SCC TU $n=9$ ). (C) Bars represent increased mRNA expression of IL-10 in CTR lung region of patients who suffered from SCC compared with the TU of SCC patients (ADC CTR $n=14$; ADC TU $n=14$, SCC CTR $n=7$; SCC TU $n=8$ ). (D) Correlation of IL-10 mRNA level and the maximal tumour diameter $(\mathrm{cm})$ in ADC CTR and NSCLC CTR. Coincident pairs ADC CTR $n=14$, coincident pairs NSCLC CTR $n=21$. (E) IHC staining on paraffin-embedded tissue sections of tumour and control region from patients, who suffered from ADC, was performed with anti-IL-10 (brown) and anti-CD3 (blue) antibodies. (F) Immunostaining on paraffin-embedded tissue sections of tumour and control region from patients who suffered from SCC were performed with anti-IL-10 (brown) and anti-CD3 (blue) antibodies. (G) Quantification of enhanced CD3 accumulation in TU of patients who are suffering from ADC compared with the related CTR (ADC CTR $n=10 ; A D C$ TU $n=8, S C C$ CTR $n=9$; SCC TU $n=9$ ). Data are shown as mean values \pm s.e.m. using Student's $t$-test ${ }^{\star} P<0.05,{ }^{\star \star} P<0.01$ and ${ }^{\star \star \star} P<0.001$. IHC stainings are shown at $\times 20$ magnifications by using the Case Viewer software and expanded square at $\times 30$.

macrophages type 2 in tumour, which then activate $\mathrm{IL}-10 \mathrm{R}^{+}$ T-cells, which are mainly Foxp- $3^{+}$T-cells. PDL1, which is expressed in macrophages and in tumour cells inversely correlated with IL-10R in the control region of ADC (Figure 4B), but directly correlated with SCC (Figure 4B, right-hand side). Upon cell activation, T-cells undergo under metabolic reprogramming, a process that require the activation of the glycolysis. We next found that HIF1- $\alpha$ correlated with IL-10R in the control region of SCC (Figure 4C), knowing that HIF1- $\alpha$ can cause metabolic cell reprogramming in cancer (DeBerardinis et al, 2008). It is possible that IL-10R on T-cells directly correlated with HIF1- $\alpha$ expression in the control region of patients with SCC. In conclusion, in SCC during tumour growth, PDL1 and HIF1- $\alpha$ directly correlated with IL-10R. By contrast, in ADC, IL-10R inversely correlated with PDL1 in ADC.

IL-10R and PD1 inversely correlated in the tumoural region of patients with ADC. We next asked about the relationship between PD1 and IL-10R, and confirmed that PD1 was induced in the tumour area, whereas IL-10R was induced in the control area of both ADC and SCC (Figure 5A). Moreover, in confirmation of this finding, we discovered a strong statistically significant inverse correlation between IL-10R and PD1 in the tumoural area of patients with ADC in particular and in patients with NSCLC in general (Figure 5B). These data suggest an inhibitory function of IL-10 on PD1 expression via the IL-10R.

Translational studies in a murine model of lung ADC confirmed the presence of IL-10R on Foxp-3 ${ }^{+}$Treg in the lungs of tumourbearing mice. We next tried to recapitulate the results in humans, by using a murine model of lung cancer. Here we injected intravenously the lung ADC cells LL/2-luc-M38 containing the Firefly luciferase gene expressed from the PCI-luc promoter and analysed the tumour load by using an in vivo imaging based on luminometer (Figure 5C). We then analysed Foxp $-3^{+}$Treg cells for IL-10R expression. As in humans, lung tumour-infiltrating Foxp- $3^{+}$Treg cells carrying IL-10R were induced in the lung of mice bearing tumour (Figure $5 \mathrm{C}$ ). 

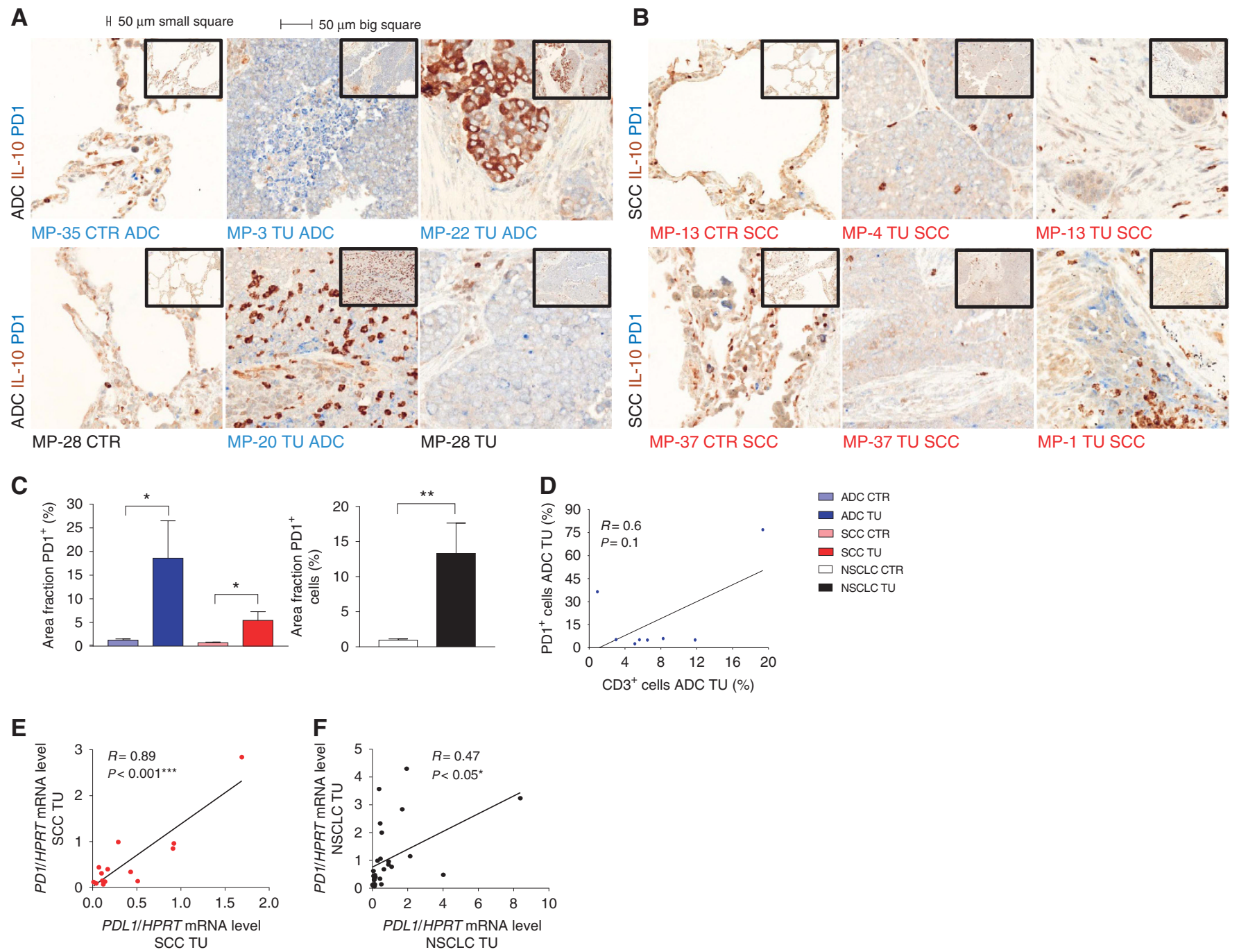

Figure 2. Enhanced and directly correlated PD1 and CD3 expression in the tumoural region in NSCLC, especially in ADC. Immunostainings are represented at $\times 40$ magnifications (and in the upper left square a reduction is shown at $\times 20$ ) by using the computer program Case Viewer. (A and B) Paraffin-embedded lung tissue slices of the pathological verified CTR and TU from patients who suffered from ADC were immunohistochemically stained with $\alpha \mathrm{lL}-10$ and $\alpha$ PD1 antibodies. ADC CTR $n=12 ;$ ADC TU $n=9$ and SCC CTR $n=9$; SCC TU $n=9$, respectively. (C) Quantification of PD1 ${ }^{+}$cells in NSCLC patients. ADC CTR $n=10$; ADC TU $n=10$; SCC CTR $n=9$; SCC TU $n=9$. (D) Correlation between the area fraction of $\mathrm{PD}^{+}$and $\mathrm{CD}^{+}$cells in TU of patients who suffered from ADC. Coincident pairs ADC TU $n=8$. (E) Correlation between PD1 mRNA level and PDL1 mRNA level in the TU of patients with SCC. Coincident pairs $n=14$. (F) Correlation between PD1 mRNA level and PDL1 mRNA level in the TU of patients with NSCLC. Coincident pairs NSCLC TU $n=27$. Bar chart is shown as mean values \pm s.e.m. using Student's t-test ${ }^{\star} P<0.05,{ }^{* \star} P<0.01$ and ${ }^{* \star *} P<0.001$.

T-bet ${ }^{+} \mathrm{CXCR}^{+}$Th1-cells express PD1 in tumour-bearing mice. As PDL1 in tumour cells is known to be induced by IFN$\gamma$ and in patients with ADC we found that PD1 bearing lymphocytes are often not Foxp-3 positive, we next looked for T-cells bearing PD1. We found that, in the lung of mice bearing tumour, PD1 is induced in $\mathrm{CD} 4^{+}$T-cells expressing T-bet, the main transcription factor of IFN- $\gamma$, and in $\mathrm{CD} 4{ }^{+}$Tbet $^{+} \mathrm{CXCR}^{+}$ cells as analysed in the total cells isolated from tumour-bearing mice compared with naive mice (Figure 5D).

In conclusion, in developing lung tumour, Th1 bearing PD1 increase, thus allowing anti-PD1 treatment to limit this disease.

It is possible that PD1-bearing cells are on Th1 in lung tumour. As IL-10 is an inhibitor of IFN- $\gamma$, we concluded that the cells bearing IL-10R are distinct from Th1, in fact they are Foxp- $3^{+}$ Treg cells and tumour cells. Under these immunosuppressive conditions, the tumour grows and the environment is deprived by metabolites; under these metabolic restrictions, IL-10R is induced on tumour cells. Finally, IL-10 terminates the PD1/PDL1 signalling induced by IFN- $\gamma$, by inhibiting PD1 and PDL1 in tumour, thus resulting in resistance to anti-PD1/PDL1 treatment in patients with NSCLC.

Metabolic deprivation induced IL-10R, IL-10 decreased FASL, FAS and apoptosis, and suppressed PDL1 and PD1 on lung A549 ADC cells. Taken together, the data above indicate that the presence of tumour cells of different origin might influence the balance between IL-10R and PDL1 in metabolic restriction present in the tumour milieu of ADC. Moreover, IL-10 has an inhibitory function on PD1 or vice versa.

Therefore, we next asked whether a lung ADC cell line would be responsive to IL-10, because it expresses IL-10R. To address this point we thought to reproduce conditions present during tumour growth and thus exposed the cells to normal nutrient conditions (10\% FCS) or under limiting metabolic conditions present during 
A

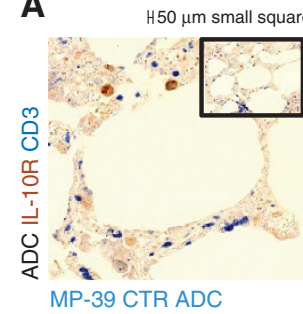

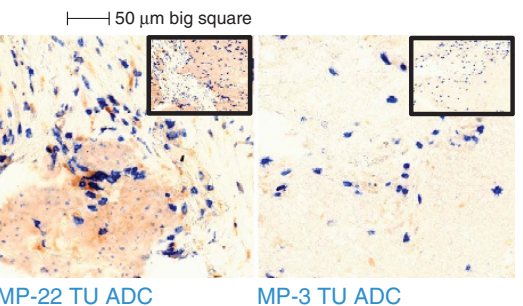

MP-22 TU ADC
B

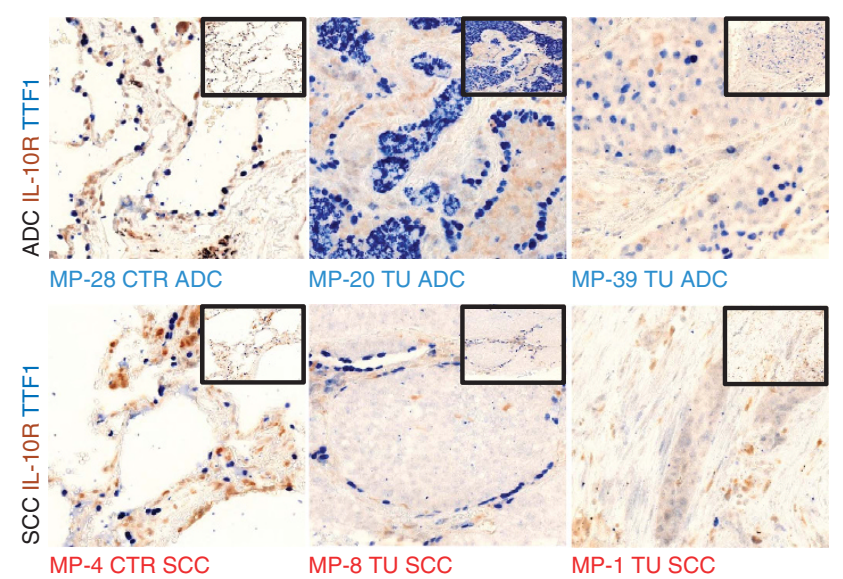

C
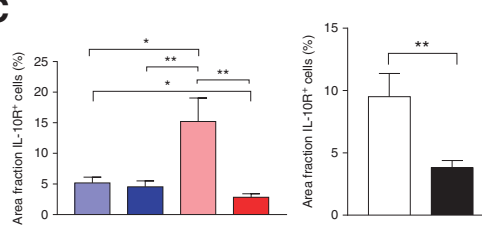

D
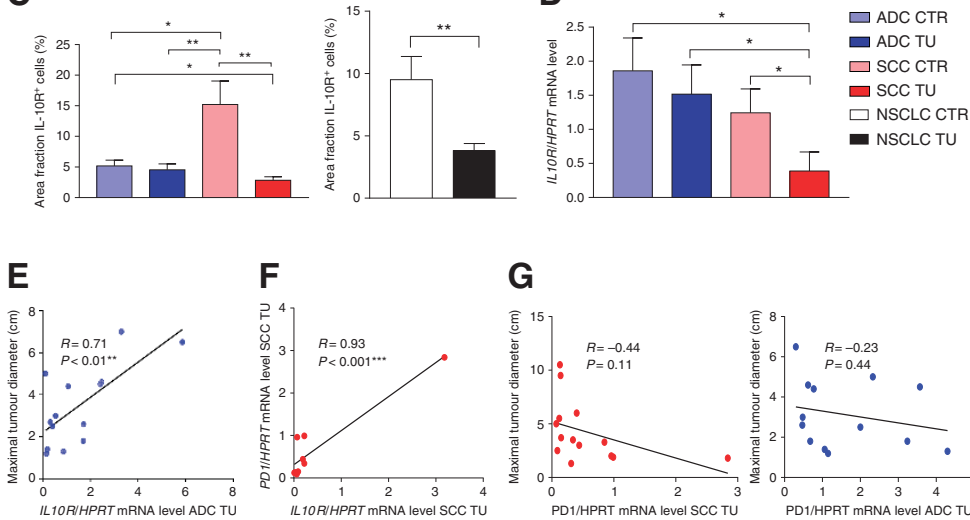

G

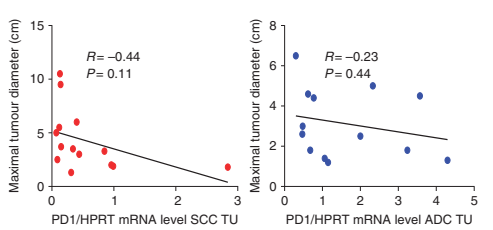

H
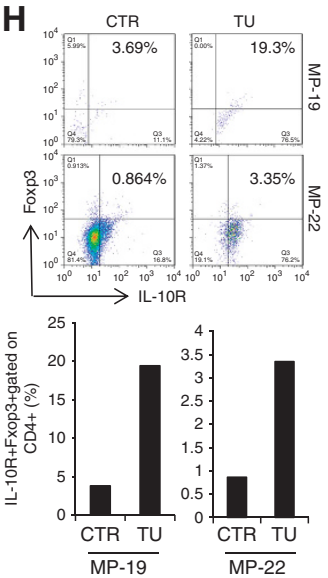
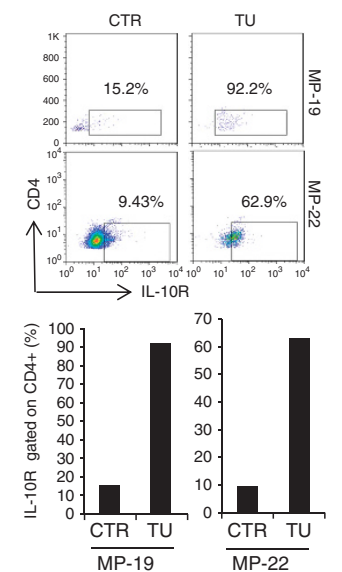

Figure 3. IL-10R directly correlated with the tumour diameter and PD1 and is upregulated in Foxp- $3^{+}$Treg cells infiltrating the tumoural region of patients with ADC. Immunostaining is shown at $\times 40$ magnifications and in the upper square at $\times 20$ magnifications, by using the computer program Case Viewer. (A) Immunostaining of IL-10R (brown) and CD3 (blue) was performed on paraffin-embedded tissue sections from CTR and TU of patients who suffered from ADC or SCC. (B) Immunostaining of IL-10R (brown) and TTF1 (blue) was performed on paraffin-embedded tissue sections from CTR and TU of patients who suffered from ADC or SCC. (C) Combined quantification of IL-10R ${ }^{+}$cells from these two presented stainings in NSCLC patients. ADC CTR $n=10$; ADC TU $n=8$; SCC CTR $n=9$; SCC TU $n=9$. (D) qPCR verified decreased mRNA expression level of IL-1OR in the TU in patients who suffered from SCC. ADC CTR $n=14$; ADC TU $n=14$; SCC CTR $n=11$; SCC TU $n=11$ (E) Correlation of IL-10R mRNA and the maximal tumour diameter $(\mathrm{cm})$ in ADC TU. Coincident pairs ADC TU $n=21$. (F) In the TU of patients who suffered from SCC a direct correlation was detected between IL-10R and PD1 mRNA. Coincident pairs $n=9$. (G) No correlation of PD1 mRNA level and maximal tumour diameter in the TU of SCC (coincident pairs $n=14$ ) and ADC (coincident pairs $n=13$ ). (H) Accumulation of IL-10R ${ }^{+}$Foxp- $3^{+}$lymphocytes in the TU compared with the CTR of patients who suffered from ADC. ADC CTR $n=2 ; A D C T U n=2$. Bar charts are shown as mean values \pm s.e.m. using Student's t-test ${ }^{*} P<0.05,{ }^{* *} P<0.01$ and ${ }^{* \star *} P<0.001$.

tumour growth. Here we saw that, the human A549 ADC cell line cultured with $10 \%$ serum had lower levels of IL-10R as compared with the one cultured under low level of nutrients such as $0.4 \%$ FCS (Figure 6A). We thus concluded that limiting metabolic nutrients promotes IL-10 signal transduction in lung tumour. In fact, by adding IL-10 to the tumour ADC cell line, under metabolic restriction, we observed a significant upregulation of STAT3 as well as phosphorylated STAT3 (Figure 6B) intracellularly and a downregulation of the apoptosis marker Annexin V (Figure 6C). Even under normal conditions (no metabolic restriction Figure 6D-G), IL-10 inhibited the apoptotic pathway by inhibiting FASL (Figure 6D) and FAS (Figure 6E), consistent with the human data in ADC. In summary, IL-10 inhibited tumour cell apoptosis and cell apoptosis markers such as FAS, FASL and Annexin V in the human tumour A549 ADC cells, thus favouring lung tumour cell growth. Under normal growing conditions in $10 \%$ FCS, IL-10 inhibited PD1 (Figure 6F) and PDL1 (Figure 6G) on these human lung ADC cells. Thus IL-10 emerges as a possible marker to identify when anti-PD1 treatment would work.

\section{DISCUSSION}

The demand on novel treatment options for the most life threatening cancer type, lung cancer, is obvious. Further research is inalienable to provide innovative therapy approaches and a powerful, pleiotropic signal transducer such as IL-10 might be a promising starting point for prospective investigations and therapy considerations, especially in the context with the presently, intensively investigated targets such as PDL1 and PD1 providing a plurality of new cancer treatments.

IL-10 is a frequently already examined cytokine; however, in the past, the focus was mainly placed on its immunosuppressive, protumoural potential (Sharma et al, 1999), while presently more and more additional anti-tumoural properties, depending on its application, were revealed and it is even used as anti-tumoural medication (Teng et al, 2011).

However, its mode of functioning is obviously multisided. We have recognised noticeable differences in the accumulation 

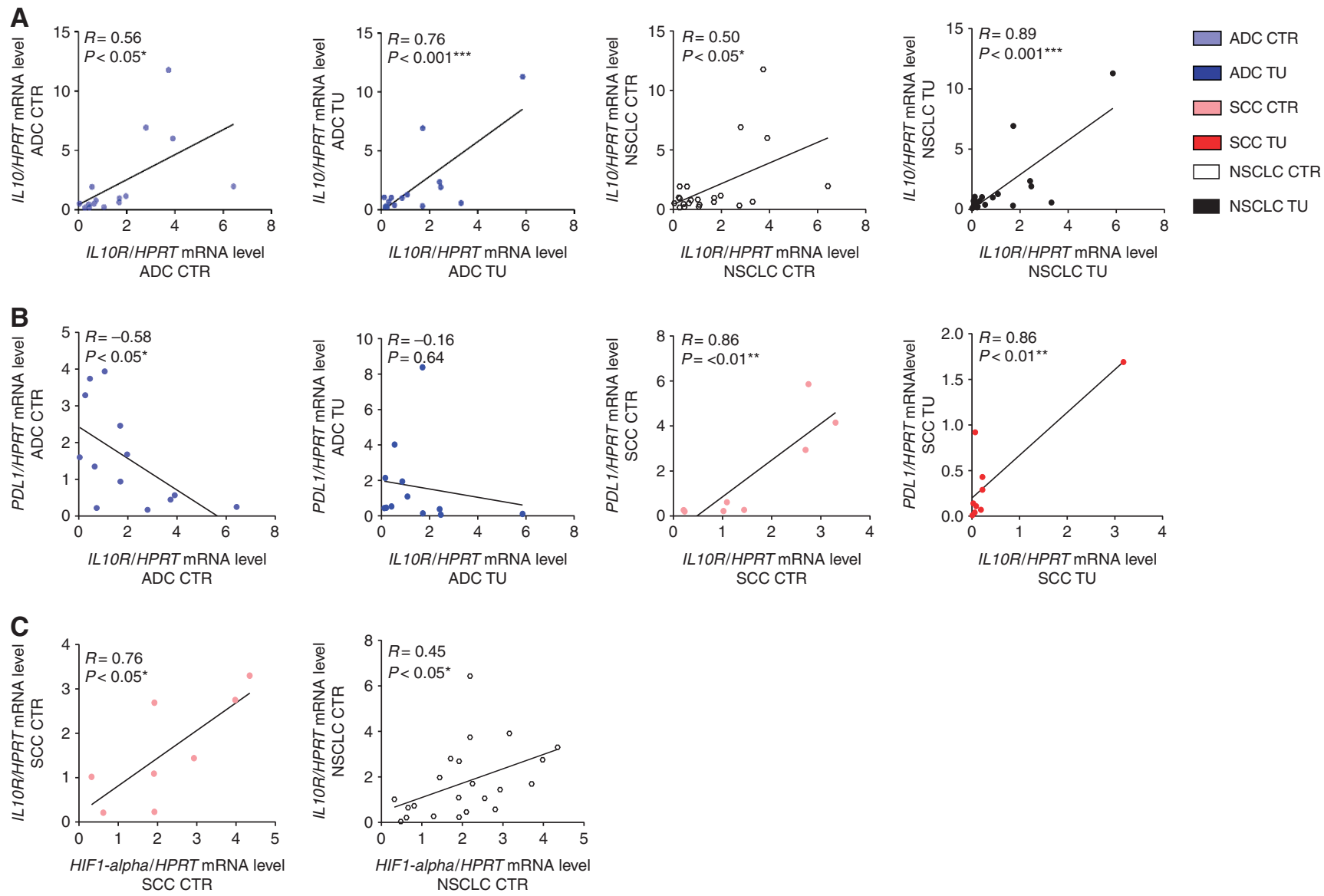

Figure 4. IL-10 and IL-10R directly correlated in NSCLC and in SCC, but not in ADC, IL-10R directly correlated with PDL1 and HIF1 $\alpha$.

(A) Correlation of IL-10R mRNA level and IL-10 in ADC CTR (coincident pairs $n=14$ ) and TU (coincident pairs $n=14$ ) and between IL-10R and NSCLC CTR (coincident pairs $n=21$ ) and TU (coincident pairs $n=22$ ). (B) Correlation of IL-10R mRNA level and PDL1 in NSCLC. Coincident pairs ADC CTR $n=13$, coincident pairs ADC TU $n=12$, coincident pairs SCC CTR $n=8$, coincident pairs SCC TU $n=9$. (C) Correlation of HIF1-alpha mRNA level and IL-10R in SCC CTR (coincident pairs $n=8$ ) and NSCLC CTR (coincident pairs $n=22$ ). Bar chart is shown as mean values \pm s.e.m. using Student's t-test ${ }^{*} P<0.05,{ }^{*} P<0.01$ and ${ }^{* \star *} P<0.001$.

patterns of IL-10-producing cells and its addressees among the human lung biopsy studies, which raises the question how this compartmentalisation is generated and what is their meaning. Our data show commonly by trend elevated levels of IL-10 and IL-10R in the NSCLC control region. Concerning the increase of IL-10, in NSCLC CTR region, especially in ADC, we found a positive correlation between IL-10 and the tumour diameter. Therefore, these results seem to highlight the impact of an IL-10-producing cell accumulation in the control region of the lung of patients carrying lung cancer, which should be examined carefully to understand IL-10 assisted tumour expansion. This thought is supported by the fact that the number of IL-10-producing TAMs, located in the CTR region, which can be morphologically retraced in our IHC pictures, correlates with poor prognosis (Zeni et al, 2007). On the subtended TU side of NSCLC, we see elevated levels of PD1 and CD3, typical for lung cancer stroma (Banat et al, 2015), being predominant especially in the lung tumoural region of patients with ADC. Among these cells, might be CD3 elevated PD1 elevated T-cells, likely a large amount of exhausted T-cells (Wherry, 2011). Thus, how do those two clusters arise and interact together (increased IL-10 and IL-10R in the CTR on the one hand and elevated CD3 and PD1 in the TU on the other hand)?

In our poly-phase model of the impact of IL-10 in lung ADC we hypothesise the following context: tumoural antigens trigger IFN$\gamma$-mediated Th1 answer, which is meant to impair tumour development and maintain homeostasis (Hubackova et al, 2016), but via tumour escape mechanisms IFN- $\gamma$ leads to tumoural PDL1 upregulation (Mandai et al, 2016). PDL1 promotes the accumulation and function of Tregs (Francisco et al, 2009; Chen et al, 2016b), as well as the accumulation of exhausted, PD1 expressing Th cells (Zun-Qiang Zhou et al, 2016), which is underlined by our transcription analysis showing positive correlation between PDL1 and PD1 in NSCLC TU, as well as the upregulation of the IL-10R in Foxp- $3^{+}$TU-infiltrating T-cells, shown in our flow cytometric analysis of human ADC biopsies. These anti-inflammatory cells support an IL-10 high, immunosuppressive tumour environment. An IL-10 high microenvironment supports further accumulation of immunosuppressive cells such as TAMs in the CTR region, exhausted Th cells and Tregs expressing IL-10R in the TU region correlating with increased tumour growth, as well as poor prognosis regarding IL-10R ${ }^{+}$and Foxp- $3^{+}$Treg TU infiltration (Tao et al, 2012), and also hinders differentiation and accumulation of anti-tumoural cells such as M1 macrophages, fully functional Th1-cells, NK cells and APC (Sharma et al, 1999; Krneta et al, 2017).

After the establishment of a stable, IL-10 dominated, immunosuppressive environment and a resulting downregulation of tumoural PDL1, even medical anti-tumoural anti PDL1/PD1 treatment might be less useful. Those directly IL-10R/STAT3 mediated, tumoural surface characteristics modulating and 
A

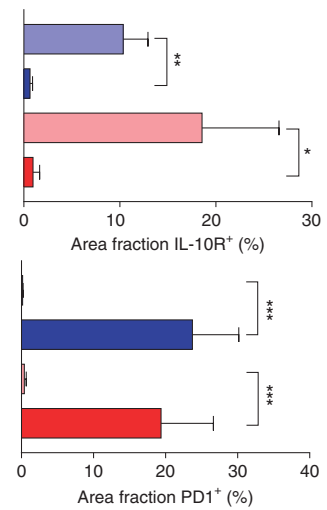

B

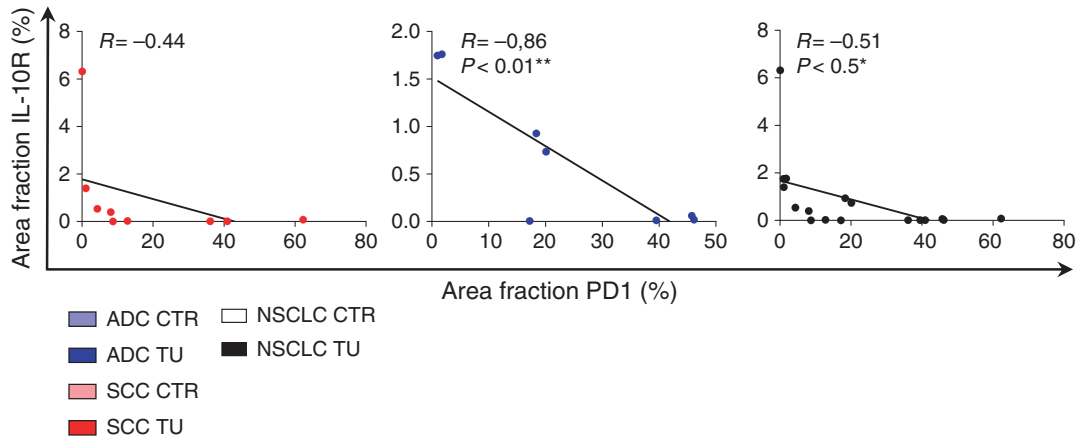

C
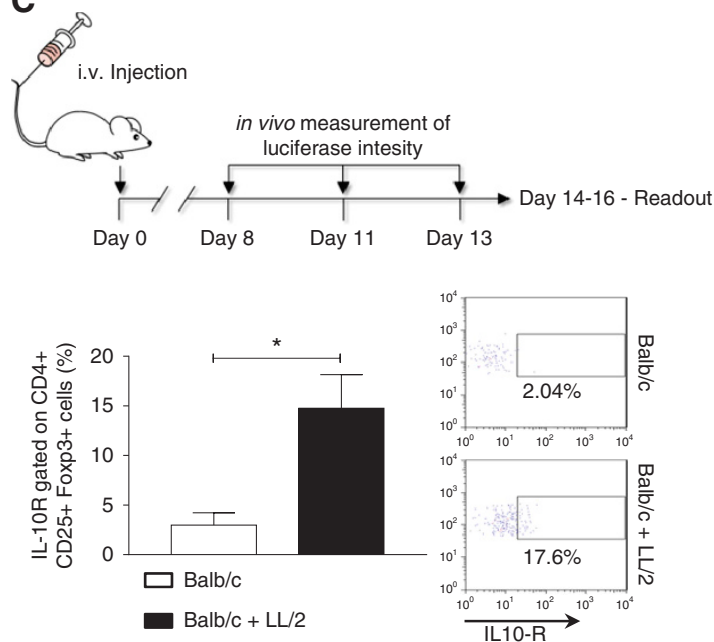

D

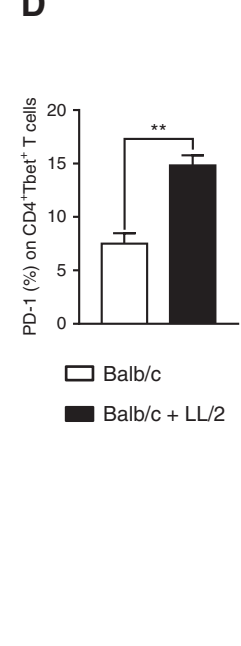

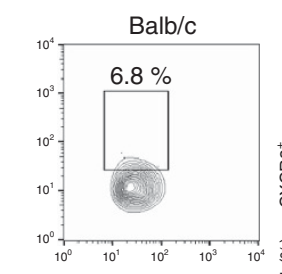

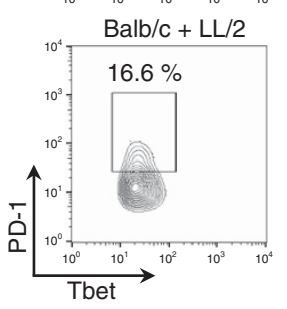

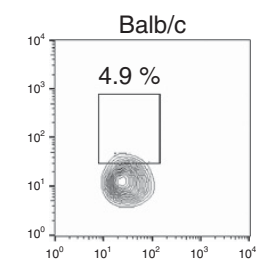

$\mathrm{Balb} / \mathrm{c}+\mathrm{LL} / 2$

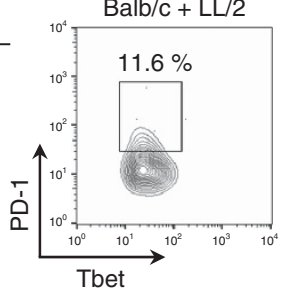

Figure 5. IL-10R and PD1 inversely correlated in the tumoural region of patients with ADC. (A) Bar charts represent the positive stained area fraction of IL-10R (upper graph) and PD1 (lower graph) in tumoural and control region of patients who suffered from ADC. ADC CTR $n=10, A D C$ TU $n=8$, SCC CTR $n=9$, SCC TU $n=9$. (B) Correlation of the area fraction of IL-10R and area fraction of PD1 in the tumoural region and control region from patients with $A D C$ and $S C C$, as well as an overview of the tumoural region and control region from all patients who suffered from NSCLC. Bar chart is shown as mean values \pm s.e.m. using Student's t-test ${ }^{*} P<0.05,{ }^{*} P<0.01$ and ${ }^{\star \star \star} P<0.001$. Translational studies confirmed the induction of IL-10R on Foxp-3 ${ }^{+}$Tregs and PD1 on Th1 cells in mice bearing lung tumour compared with naive mice. (C) Experimental design of the ADC-based murine lung cancer model. ( $D$, left) PD1 expression, analysed by flow cytometry, is increased in CD4 + T-bet + cells and (D, right) CXCR3 + cells isolated from lungs from tumour bearing mice compared with naive mice. Balb/c $n=3 ;$ Balb/c + LL/2 $n=4$. (D) Flow cytometric analysis showed an accumulation of IL10R ${ }^{+}$Tregs in lungs of tumour bearing mice compared with naive mice. Balb/c $n=5$;

Balb/c $+\mathrm{LL} / 2 n=6$. Data are shown as mean values \pm s.e.m. using Student's t-test ${ }^{*} P<0.05, * \star P<0.01$ and ${ }^{* \star *} P<0.001$.

antiapototical effects might be bigger, the faster the tumour is growing, when going along with a nutrient starvation and rise of HIF1- $\alpha$, which was especially found in SCC CTR and is followed by an IL-10R sensitisation. Once, the IL-10 liberation is overbalanced the enforcement of an immunosuppressive environment seems unstoppable regarding the observed positive correlation between IL-10 and IL-10R, supported by other findings, that IL-10 can induce IL-10 in monocytes (Staples et al, 2007), maybe advantaged by a possible decrease of negative feedback via SOCS3 because of SOCS3 promoter hypermethylation (Lin et al, 2010). FASL is assumed to behave similarly and mediate similar effects in comparison with PDL1. This could be the subject of further studies.

Unfortunately, this model is not fully able to explain the more malignant (Fry et al, 1999) human situation in SCC regarding the differences in IL-10, IL-10R, PD1, CD3 expression and correlation analysis compared with ADC. A key reason for this difference could be that in SCC CTR and TU region we do not see a negative correlation between the IL-10R and PDL1 but a positive one. This leads to our suggestion that there might be no negative feedback concerning IL-10 and PDL1 like we found in ADC but the opposite. The absence of negative feedback means increased apoptosis of CD3 elevated Th1-cells via PD1 (Ji et al, 2016), leading to a poor prognosis (Kinoshita et al, 2016), which could explain the depressed levels of CD3 in SCC TU compared with ADC TU and implies more likely an assumed interaction and promotion of IL10-producing Foxp- $3^{+} \mathrm{CD} 4^{+} \mathrm{T}$-cells, than with exhausted Th1cells such as in ADC. These Foxp ${ }^{+}$T-cells are frequently increased and often permanently activated in NSCLC (Ke et al, 2016) and usually express PD1 (Gao et al, 2012) as well as IL-10R (Chaudhry et al, 2011). This could be the reason why we see a positive correlation between PDL1 and PD1 in SCC TU, as well as between PD1 and IL-10R in SCC TU, between PDL1 and IL-10R in SCC TU and CTR, and finally why there are higher levels of PDL1 in general in SCC (Jiang et al, 2016) than in ADC. In SCC patients with high levels of PDL1 have a poor prognosis (Ferlay et al, 2015; Sundar et al, 2015), if untreated. We assume, as they are supposed to lack the IL-10-mediated downregulation mechanism of PDL1, meaning the absence of the anti-PDL1/PD1 treatment resistance functionality, these patients therefore may have a higher use of 
A

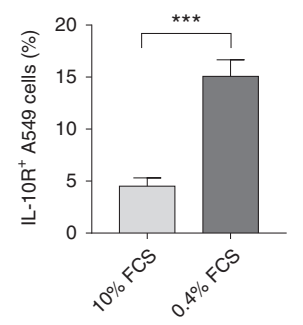

D

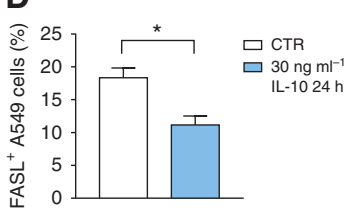

E
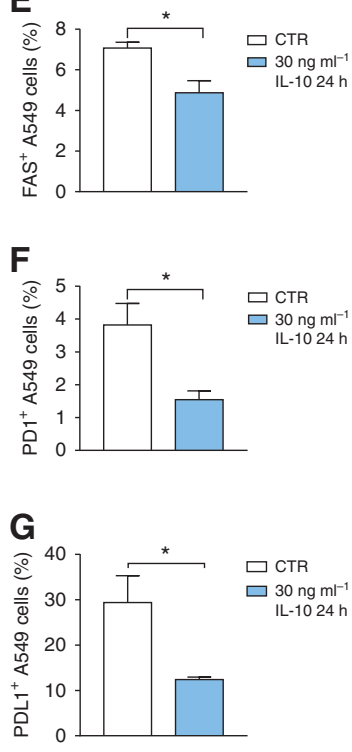
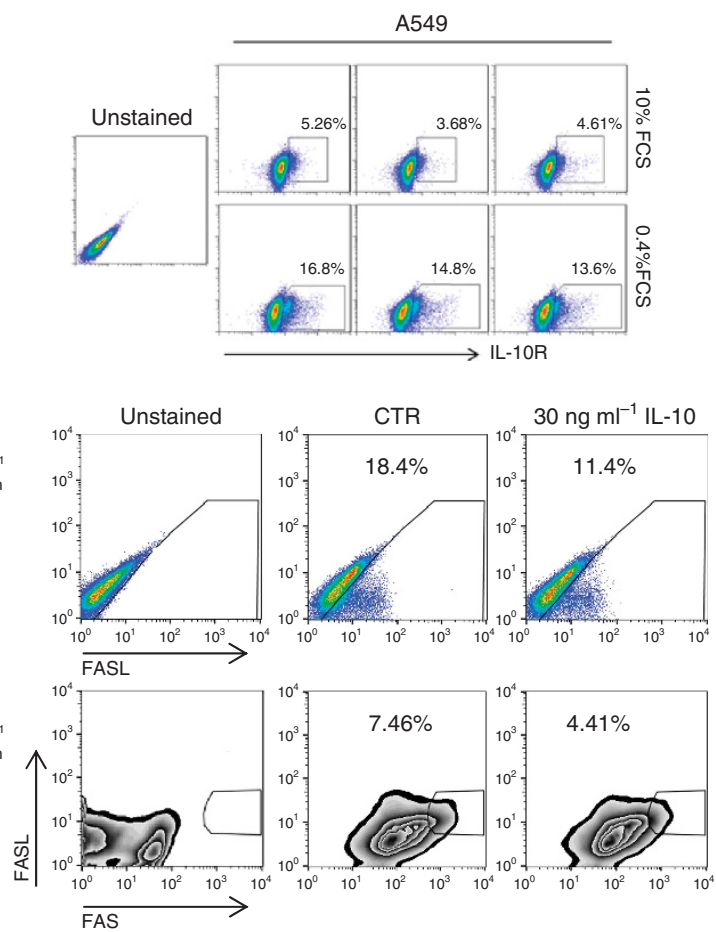

FAS
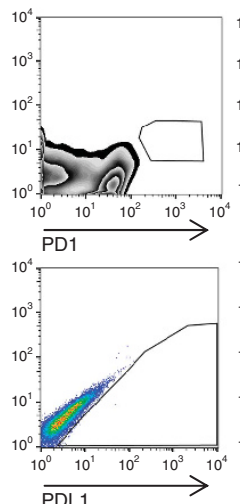
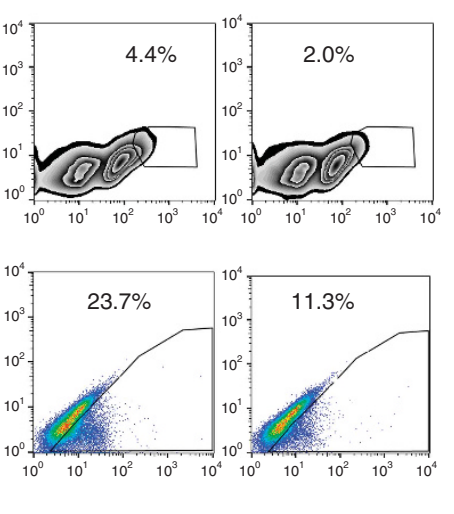

B
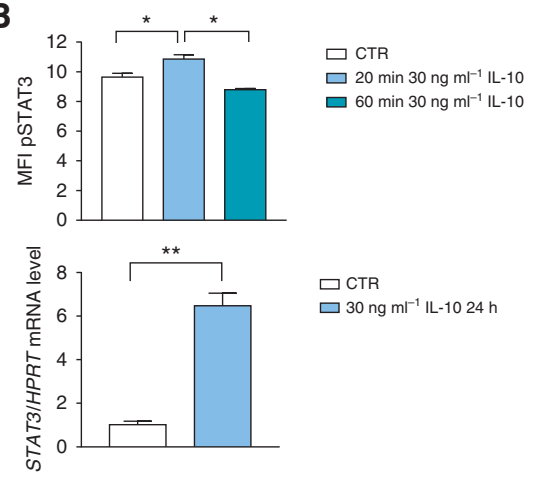

$\square$ CTR

$\square 30 \mathrm{ng} \mathrm{ml}^{-1} \mathrm{IL}-1024 \mathrm{~h}$

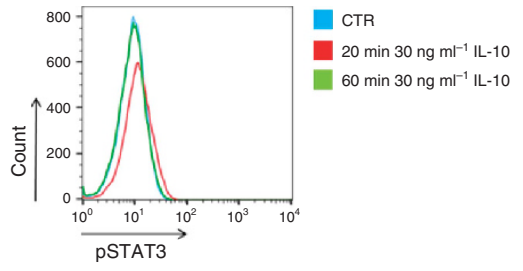

C
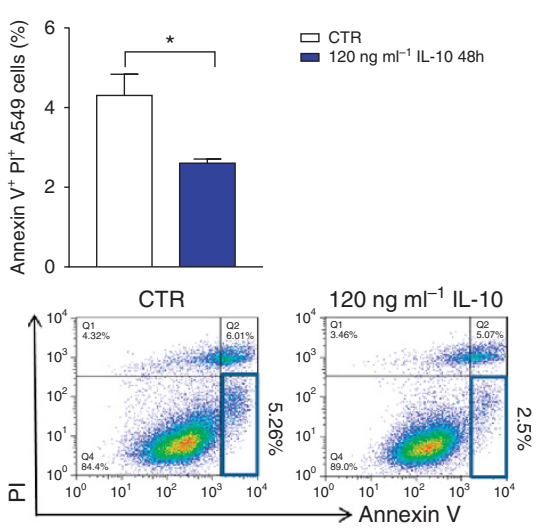

Figure 6. Metabolic deprivation induced IL-10R. IL-10 decreased PDL1, PD1, FASL, FAS and tumour cell apoptosis on lung ADC cells. (A) Flow cytometric analysis showed that serum starvation or metabolic deprivation (0.4\% FCS) induced IL-10R on A549 cells compared with $10 \%$ FCS treatment ( $n=3$ per condition). (B) Treatment of serum starved A549 cells with IL-10 leads to an upregulation of pSTAT3 measured by flow cytometric analysis and verified on RNA level by qPCR ( $n=3$ per condition). (C) A549 cells treated with IL-10 showed a significant reduction of apoptosis as shown by decreased Annexin $\mathrm{V}$, a marker of cell apoptosis, under metabolic deprivation compared to the non-treated control cell cultures; ( $n=3$ per condition). (D) FASL, the ligand of FAS (E), a cell apoptosis ligand-receptor, were reduced in A549 by IL-10 treatment under normal metabolic conditions (10\% FCS), ( $n=4$ per condition). A549 cells cultured with $10 \%$ FCS were treated with IL-10 downregulated the expression of PD1 (F), PDL1 (G) compared with the non-treated control, by flow cytometry ( $n=4$ per condition). Data are shown as mean values \pm s.e.m. using Student's $t$-test ${ }^{\star} P<0.05,{ }^{\star \star} P<0.01$ and ${ }^{\star \star *} P<0.001$.

anti-PD1/PDL1 therapy (Reck et al, 2016). Anyway, we could not detect a positive correlation between PD1 and tumour diameter in NSCLC TU.

In summary, countering the overbalance of IL-10-producing cells in the CTR of NSCLC to stop IL-10-mediated tumour immune tolerance, which correlates with tumour growth, reaction to chemotherapeutics and prognosis may lead to a better outcome. There are already therapeutics in use such as the recommended PD1 inhibitors Nivolumab and Pembrolizumab (Ettinger et al, 2016), which achieve this goal by stopping T-cells from being impaired via tumoural PDL1, and leading to a higher level of IFN- $\gamma$, which also blocks IL-10 release. However, remarkably, also exogen liposomal PEG-IL-10, which is purposively flushed out in the TU because of fast growing, insufficient constructed vessels, leads to similar effects such as PD1-antagonists and rises $\mathrm{CD}^{+}$T-cell cytotoxity, promotes $\mathrm{CD}^{+}$T-cell accumulation, and IFN- $\gamma$ and granzyme release in the tumoural region (Teng et al, 2011; Naing et al, 2016b). The mechanism seems unclear having all the immunosuppressive effects of IL-10 in mind.

Concerning immunotherapeutic intentions, we think a combination of PEG-IL-10 and PD1-antagonists could have a synergistic effect and might be a potent weapon against the devastating effect of tumoural PDL1 in NSCLC (Naing et al, 2016b), whereas PEGIL-10 might be less useful in SCC, but especially useful in ADC. Besides those two, other antibody strategies would be thinkable according to our tumour model like the use of PDL1-AB (Antonia et al, 2016), IL10R-AB (Ni et al, 2015; Chen et al, 2016a) and IL$10-\mathrm{AB}$, whereupon current used IL-10-AB do not decrease but increase the level of IL-10 and are not used yet in NSCLC (Llorente 
et al, 2000). Furthermore, beside those primarily therapeutic intentions, IL-10 could possibly be used as a diagnostic parameter in $\mathrm{ADC}$ for anti-PD1/PDL1 treatment success forecast, whereas lower levels of IL-10 might go along with a lower anti-PD1/PDL1 resistance and better prognosis.

\section{ACKNOWLEDGEMENTS}

We thank Bettina Klösch, Corinna Holzinger and Rebekka Springel for their excellent experimental help. This work was financially supported by an IZKF grant number A59 in Erlangen awarded to SF. JMV was supported by a fellowship on Cellular Immuneintervention in Erlangen, sponsored by the graduated school of the SFB-643 group in Erlangen. We thank the all supporting team in the Molecular Pneumology department, Thoracic Surgery and Institute of Pathology in Erlangen.

\section{CONFLICT OF INTEREST}

The authors declare no conflict of interest.

\section{AUTHOR CONTRIBUTIONS}

JMV did the histological and immune-histological analysis including correlations, did the A549 experiments and wrote the manuscript, and generated the figures. JF helped with the generation of the figures and with the patients sample collection. LB did the real-time PCR for IL-10 and IL-10R in patients. DIT and HS provided and indexing the human lung biopsies. RR, CG and NF did the pathological characterization and digitalisation of the human tissue arrays originated from those biopsies, as well as the quality control of slides, stains and scans. SM did the immunohistochemical staining. LH and KK contributed to the patient samples collection and did the FACS analysis on human and in murine lung cells. LH and NS supported JMV and ST in the planning and executing numerous experiments related to the cell line A549. SF designed and supervised this study, and contributed significantly to the manuscript and figures.

\section{REFERENCES}

Almatroodi S, McDonald C, Darby I, Pouniotis D (2016) Characterization of M1/M2 tumour-associated macrophages (TAMs) and Th1/Th2 cytokine profiles in patients with NSCLC. Cancer Microenviron 9(1): 1-11.

Antonia S, Rizvi N, Brahmer J, Ou S-H, Khleif SN, Hwu W-J, Gutierrez M, Schoffski P, Hamid O, Weiss J (2016) Abstract A047: Safety and clinical activity of durvalumab (MEDI4736), an anti-programmed cell death ligand-1 (PD-L1) antibody, in patients with non-small cell lung cancer (NSCLC). Cancer Immunol Res 4(1 Supplement): A047-A047.

Banat G-A, Tretyn A, Pullamsetti SS, Wilhelm J, Weigert A, Olesch C, Ebel K, Stiewe T, Grimminger F, Seeger W (2015) Immune and inflammatory cell composition of human lung cancer stroma. PLoS One 10(9): e0139073.

Besse B, Adjei A, Baas P, Meldgaard P, Nicolson M, Paz-Ares L, Reck M, Smit E, Syrigos K, Stahel R (2014) 2nd ESMO Consensus Conference on Lung Cancer: non-small-cell lung cancer first-line/second and further lines of treatment in advanced disease. Ann Oncol 25(8): 1475-1484.

Chaudhry A, Samstein RM, Treuting P, Liang Y, Pils MC, Heinrich J-M, Jack RS, Wunderlich FT, Brüning JC, Müller W (2011) Interleukin-10 signaling in regulatory $\mathrm{T}$ cells is required for suppression of Th17 cellmediated inflammation. Immunity 34(4): 566-578.

Chen S, Ni G, Wu X, Zhu B, Liao Z, Wang Y, Liu X (2016a) Blocking IL-10 signalling at the time of immunization renders the tumour more accessible to $\mathrm{T}$ cell infiltration in mice. Cell Immunol 300: 9-17.
Chen W-J, Hu X-F, Yan M, Zhang W-Y, Mao X-B, Shu Y-W (2016b) Human umbilical vein endothelial cells promote the inhibitory activation of CD4+ CD25 + Foxp3 + regulatory T cells via PD-L1. Atherosclerosis 244: 108-112.

Coussens LM, Werb Z (2002) Inflammation and cancer. Nature 420(6917): $860-867$.

DeBerardinis RJ, Lum JJ, Hatzivassiliou G, Thompson CB (2008) The biology of cancer: metabolic reprogramming fuels cell growth and proliferation. Cell Metab 7(1): 11-20.

Dennis KL, Blatner NR, Gounari F, Khazaie K (2013) Current status of IL-10 and regulatory T-cells in cancer. Curr Opin Oncol 25(6): 637.

Ettinger DS, Wood DE, Akerley W, Bazhenova LA, Borghaei H, Camidge DR, Cheney RT, Chirieac LR, D’Amico TA, Dilling TJ (2016) NCCN guidelines insights: non-small cell lung cancer, version 4.2016. J Natl Compr Canc Netw 14(3): 255-264.

Ferlay J, Soerjomataram I, Dikshit R, Eser S, Mathers C, Rebelo M, Parkin DM, Forman D, Bray F (2015) Cancer incidence and mortality worldwide: sources, methods and major patterns in GLOBOCAN 2012. Int J Cancer 136(5): E359-E386.

Francisco LM, Salinas VH, Brown KE, Vanguri VK, Freeman GJ, Kuchroo VK, Sharpe AH (2009) PD-L1 regulates the development, maintenance, and function of induced regulatory T cells. J Exp Med 206(13): 3015-3029.

Fry WA, Phillips JL, Menck HR (1999) Ten-year survey of lung cancer treatment and survival in hospitals in the United States. Cancer 86(9): 1867-1876.

Gao X, Zhu Y, Li G, Huang H, Zhang G, Wang F, Sun J, Yang Q, Zhang X, Lu B (2012) TIM-3 expression characterizes regulatory T cells in tumor tissues and is associated with lung cancer progression. PLS One 7(2): e30676.

Goldstraw P, Crowley J, Chansky K, Giroux DJ, Groome PA, Rami-Porta R, Postmus PE, Rusch V, Sobin L, Committee IAftSoLCIS (2007) The IASLC Lung Cancer Staging Project: proposals for the revision of the TNM stage groupings in the forthcoming (seventh) edition of the TNM Classification of malignant tumours. $J$ Thorac Oncol 2(8): 706-714.

Hatanaka H, Abe Y, Kamiya T, Morino F, Nagata J, Tokunaga T, Oshika Y, Suemizu H, Kijima H, Tsuchida T (2000) Clinical implications of interleukin (IL)-10 induced by non-small-cell lung cancer. Ann Oncol 11(7): 815-819.

Hatanaka H, Abe Y, Naruke M, Tokunaga T, Oshika Y, Kawakami T, Osada H, Nagata J, Kamochi J-i, Tsuchida T (2001) Significant correlation between interleukin 10 expression and vascularization through angiopoietin/TIE2 networks in non-small cell lung cancer. Clin Cancer Res 7(5): 1287-1292.

Huang M, Stolina M, Sharma S, Mao JT, Zhu L, Miller PW, Wollman J, Herschman H, Dubinett SM (1998) Non-small cell lung cancer cyclooxygenase-2-dependent regulation of cytokine balance in lymphocytes and macrophages: up-regulation of interleukin 10 and down-regulation of interleukin 12 production. Cancer Res 58(6): 1208-1216.

Hubackova S, Kucerova A, Michlits G, Kyjacova L, Reinis M, Korolov O, Bartek J, Hodny Z (2016) IFN $\gamma$ induces oxidative stress, DNA damage and tumor cell senescence via TGF $\beta /$ SMAD signaling-dependent induction of Nox4 and suppression of ANT2. Oncogene 35(10): 1236-1249.

Jarnicki AG, Lysaght J, Todryk S, Mills KH (2006) Suppression of antitumor immunity by IL-10 and TGF- $\beta$-producing T cells infiltrating the growing tumor: influence of tumor environment on the induction of $\mathrm{CD} 4+$ and CD8 + regulatory T cells. J Immunol 177(2): 896-904.

Ji M, Liu Y, Li Q, Li X, Ning Z, Zhao W, Shi H, Jiang J, Wu C (2016) PD-1/ PD-L1 expression in non-small-cell lung cancer and its correlation with EGFR/KRAS mutations. Cancer Biol Ther 17(4): 407-413.

Jiang L, Su X, Zhang T, Yin X, Zhang M, Fu H, Han H, Sun Y, Dong L, Qian J (2016) PD-L1 expression and its relationship with other driver genes in non-small cell lung cancer (NSCLC) Cancer Res 76(14 Suppl): abstract 5140 .

Ke X, Zhang S, Xu J, Liu G, Zhang L, Xie E, Gao L, Li D, Sun R, Wang F (2016) Non-small-cell lung cancer-induced immunosuppression by increased human regulatory $\mathrm{T}$ cells via Foxp3 promoter demethylation. Cancer Immunol Immunother 65(5): 587-599.

Kinoshita T, Muramatsu R, Fujita T, Nagumo H, Sakurai T, Noji S, Takahata E, Yaguchi T, Tsukamoto N, Kudo-Saito C (2016) Prognostic value of tumor-infiltrating lymphocytes differs depending on histological type and smoking habit in completely resected non-small cell lung cancer. Ann Oncol 27(11): 2117-2123. 
Kirby KS (1956) A new method for the isolation of ribonucleic acids from mammalian tissues. Biochem J 64(3): 405-408.

Krneta T, Gillgrass A, Poznanski S, Chew M, Lee AJ, Kolb M, Ashkar AA (2017) M2-polarized and tumor-associated macrophages alter NK cell phenotype and function in a contact-dependent manner. J Leuk Biol 101(1): 285-295.

Kuang DM, Zhao QY, Peng C, Xu J, Zhang JP, Wu CY, Zheng LM (2009) Activated monocytes in peritumoral stroma of hepatocellular carcinoma foster immune privilege and disease progression through PD-L1. J Exp Med 206(6): 1327-1337.

Lin Y-C, Lin C-K, Tsai Y-H, Weng H-H, Li Y-C, You L, Chen J-K, Jablons DM, Yang C-T (2010) Adenovirus-mediated SOCS3 gene transfer inhibits the growth and enhances the radiosensitivity of human non-small cell lung cancer cells. Oncol Rep 24(6): 1605.

Llorente L, Richaud-Patin Y, García-Padilla C, Claret E, Jakez-Ocampo J, Cardiel MH, Alcocer-Varela J, Grangeot-Keros L, Alarcón-Segovia D, Wijdenes J (2000) Clinical and biologic effects of anti-interleukin-10 monoclonal antibody administration in systemic lupus erythematosus. Arthritis Rheum 43(8): 1790-1800.

Mandai M, Hamanishi J, Abiko K, Matsumura N, Baba T, Konishi I (2016) Dual faces of IFN $\gamma$ in cancer progression: a role of PD-L1 induction in the determination of pro-and antitumor immunity. Clin Cancer Res 22(10): 2329-2334.

Montuenga L, Pio R (2007) Tumour-associated macrophages in nonsmall cell lung cancer: the role of interleukin-10. Eur Respir J 30(4): 608-610.

Naing A, Papadopoulos KP, Autio KA, Ott PA, Patel MR, Wong DJ, Falchook GS, Pant S, Whiteside M, Rasco DR (2016a) Safety, antitumor activity, and immune activation of pegylated recombinant human interleukin-10 (AM0010) in patients with advanced solid tumors. J Clin Oncol 34(29): 3562-3569.

Naing A, Papadopoulos KP, Infante JR, Wong DJ, Autio KA, Ott PA, Falchook GS, Patel M, Pant S, Patnaik A (2016b) Clinical activity and safety of PEGylated human IL-10 (AM0010) in combination with antiPD-1. Cough 2: 15.

Naruke T, Goya T, Tsuchiya R, Suemasu K (1988) Prognosis and survival in resected lung carcinoma based on the new international staging system. J Thorac Cardiovasc Surg 96(3): 440-447.

Ni G, Wang T, Walton S, Zhu B, Chen S, Wu X, Wang Y, Wei MQ, Liu X (2015) Manipulating IL-10 signalling blockade for better immunotherapy. Cell Immunol 293(2): 126-129.

Petrovic M, Cekerevac I, Lazic Z, Zdravkovic V (2013) Serum interleukin-10 levels as a prognostic factor in advanced non-small cell lung cancer patients. Eur Respir J 42(Suppl 57): P2916.

Reck M, Rodríguez-Abreu D, Robinson AG, Hui R, Csőszi T, Fülöp A, Gottfried M, Peled N, Tafreshi A, Cuffe S (2016) Pembrolizumab versus chemotherapy for PD-L1-positive non-small-cell lung cancer. N Engl J Med 375(19): 1823-1833.
Rybojad P, Jabłonka A, Wilczyńska B, Tabarkiewicz J (2013) Surgery decreases number of cells secreting cytotoxic mediators and increases secretion of interleukin 10 in patients with lung cancer. Eur J Surg Oncol 39(11): 1269-1277.

Sharma S, Stolina M, Lin Y, Gardner B, Miller PW, Kronenberg M, Dubinett SM (1999) T cell-derived IL-10 promotes lung cancer growth by suppressing both T cell and APC function. J Immunol 163(9): 5020-5028.

Staples KJ, Smallie T, Williams LM, Foey A, Burke B, Foxwell BM, Ziegler-Heitbrock L (2007) IL-10 induces IL-10 in primary human monocyte-derived macrophages via the transcription factor Stat3 J Immunol 178(8): 4779-4785.

Sundar R, Cho B-C, Brahmer JR, Soo RA (2015) Nivolumab in NSCLC: latest evidence and clinical potential. Ther Adv Med Oncol 7(2): 85-96.

Tao H, Mimura Y, Aoe K, Kobayashi S, Yamamoto H, Matsuda E, Okabe K, Matsumoto T, Sugi K, Ueoka H (2012) Prognostic potential of FOXP3 expression in non-small cell lung cancer cells combined with tumorinfiltrating regulatory T cells. Lung Cancer 75(1): 95-101.

Teng MW, Darcy PK, Smyth MJ (2011) Stable IL-10: a new therapeutic that promotes tumor immunity. Cancer Cell 20(6): 691-693.

Wang R, Lu M, Chen H, Chen S, Luo X, Qin Y, Zhang J (2011) Increased IL-10 mRNA expression in tumor-associated macrophage correlated with late stage of lung cancer. J ExpClin Cancer Res 30(1): 1.

Wherry EJ (2011) T cell exhaustion. Nat Immunol 12(6): 492-499.

Zeng L, O'Connor C, Zhang J, Kaplan AM, Cohen DA (2010) IL-10 promotes resistance to apoptosis and metastatic potential in lung tumor cell lines. Cytokine 49(3): 294-302.

Zeni E, Mazzetti L, Miotto D, Cascio NL, Maestrelli P, Querzoli P, Pedriali M, De Rosa E, Fabbri L, Mapp C (2007) Macrophage expression of interleukin-10 is a prognostic factor in nonsmall cell lung cancer. Eur Respir J 30(4): 627-632.

Zhang H, Wang Y, Hwang ES, He Y-W (2016) Interleukin-10: an immuneactivating cytokine in cancer immunotherapy. J Clin Oncol 34(29): 3576-3578.

Zhang L, Gajewski TF, Kline J (2009) PD-1/PD-L1 interactions inhibit antitumor immune responses in a murine acute myeloid leukemia model. Blood 114(8): 1545-1552.

Zun-Qiang Zhou D-NT, Guan J, Tan H-W, Zhao L-D, Zhu Y, Yao J, Yang J, Zhang Z-Y (2016) Follicular helper T cell exhaustion induced by PD-L1 expression in hepatocellular carcinoma results in impaired cytokine expression and B cell help, and is associated with advanced tumor stages. Am J Transl Res 8(7): 2926.

This work is published under the standard license to publish agreement. After 12 months the work will become freely available and the license terms will switch to a Creative Commons AttributionNonCommercial-Share Alike 4.0 Unported License.

Supplementary Information accompanies this paper on British Journal of Cancer website (http://www.nature.com/bjc) 